\title{
Assessment of Imaging Performance and Accuracy for the Diagnostic Evaluation of Wilms Tumor in Kids in the Era of Contrast Based CT Scan with Histopathological Correlation: A Study in Tertiary Care Hospital
}

\author{
Ashraf Amirali, Jaideep Darira, Hina Pathan, Sorath Murtaza, Munaza Irshad \\ Department of Radiology, Dr. Ziauddin Hospital, Karachi, 74700, Pakistan \\ *Corresponding author: Ashraf Amirali; ashrafamirali75@gmail.com
}

Received 05 September 2021;

Accepted 24 September 2021;

Published 05 October 2021

\begin{abstract}
The aim of the study is the assessment of accuracy for the diagnostic evaluation of Wilms tumor in the pediatric population in the era of contrast-enhanced CT scan using histopathology as a gold standard. Plain and contrast-enhanced abdominal Computed Tomography including pelvis and chest was performed in suspected patients with multiple axial sections with sagittal and coronal reconstructions. Patients were being followed, data was collected and recorded on proforma after histopathology. The patient's mean age for this study in years was $3.5 \pm 1.2$. Gender distribution showed 170 patients (54.6\%) were male while the remaining 141 patients $(45.33 \%)$ were female. Contrast-enhanced computed tomography showed sensitivity (90.36\%), specificity $(51.72 \%)$, diagnostic accuracy $(72.34 \%)$, positive predictive value (68.18\%), and negative predictive value $(82.42 \%)$ confirmed on Histopathology as the gold standard. It is concluded from the results of this study that contrast-enhanced computed tomography proved high diagnostic accuracy positive predictive in the detection of Wilms' tumor by taking histopathology as the gold standard.
\end{abstract}

Keywords: Wilms tumor, accuracy, histopathology, computed tomography, children

\section{Introduction}

Most of the renal tumors in adults and children are primary, as the kidney is not the favorite site of metastasis for other malignant neoplastic lesions ${ }^{[1]}$. In children of all the malignant tumors of the kidney, Wilms' tumor, the most frequent accounts for about $95 \%$ and 500 cases annually in the USA ${ }^{[2,3]}$. Before 15 years of age, the distribution is one in 10,000 children worldwide. Generally, more of the African population of USA affects, with males affects earlier than females ${ }^{[4]}$. The tumor accounts for $13.2 \%$ of all childhood cases with major occurrence in 3-4 years of age ${ }^{[5,6]}$. In about $10 \%$ of the cases, the tumor is present on either side and among those one third are metachronous and two-thirds synchronous, hence once the tumor is found, the contralateral kidney should be carefully evaluated for the synchronous lesion ${ }^{[2]}$. The familial cases are $1 \%{ }^{[5]}$. The vast majority of cases of Wilms tumor are sporadic ${ }^{[7]}$. but in $12-15 \%$ of the event there are well-known anomalies associated with it, these are horseshoe kidney, duplicated collecting system, hypospadias, and fused kidney ${ }^{[7,8]}$. It is well-established fact that the diverse Wilms tumor has genetic association due to aberrant alteration in genes and related several types of syndromes, which was also established by Knudson model that has been later proven. The associated well-recognized syndromes are WAGR, Beck width Wiedemann syndrome, and Denys Drash syndrome. Several oncogenic mutations are well recognized, one of the intimating was of the WT1 on 11p15 locus. The other mutative genes are WTX, CTNNB, but according to analysis, all of these mutations account for only one in a third of cases ${ }^{[9]}$. Currently, other new genes are found to be involved as well. These are REST, CTR9, and TRIM28 ${ }^{[8]}$. In the past, various research studies have shown a relationship with the factors that contributed to tumor development which are related to mother's hormonal and father's occupational factors ${ }^{[4]}$. The average presentation at age concerned to one side is $42-47$ months, whereas its presents on either side at the average age of 30-33 months ${ }^{[10]}$.

The most common symptoms in the clinical presentation of most cases are the presence of high blood pressure, abdominal mass or swelling without any symptoms and encountered by the mother, pain in the abdomen, and hematuria ${ }^{[5]}$. Mostly ultrasonography is used for initial diagnosis but the sensitivity of 
CT scan is $98 \%$ and specificity is $90 \%{ }^{[11,12]}$. There are many differential diagnoses of this tumor-like hepatoblastoma, lymphoma, and neuroblastoma ${ }^{[13]}$.

Nephroblastoma is a solid tumor with a fibrous pseudocapsule on gross examination ${ }^{[14]}$. The tumor is a compound of epithelial, blastemal, and stromal constituents. The stromal part has the least proliferation whereas blastemal has the most proliferation activity and hence it should be targeted because its persistence after chemotherapy has a grave outcome. Like other tumors in the body, the active maintenance of telomerase being the main focus in this tumor as well ${ }^{[1]}$.

On CT scan, the Wilms is a well-defined heterogeneous lesion with normal parenchyma that can be seen stretching and splaying at the periphery of mass, the positive beak sign. Low attenuation area concurred with the necrosis of tumor or deposition of fat ${ }^{[14]}$. CT shows high diagnostic accuracy and is considered as a procedure of choice for staging and diagnosing renal masses in children. This study will help in determining the significance of computed tomography in making an early diagnosis of Wilms' tumor in our population and comparing its accuracy with histopathology that would be helpful in early and effective starting of treatment reduces mortality and morbidity and will offer the patient better prognosis regarding survival and quality of life.

\section{Materials and Methods}

Our prospective cross-sectional study was conducted from 1st February 2019 to 31st June 2020 in the Department of Radiology, Dr. Ziauddin University Hospital, after approval from the hospital's ethical review committee. The estimated sample size was 311 with expected sensitivity 0.92 , expected specificity 0.55 , expected prevalence 0.13 , desired precision 0.07 , and confidence level 0.95 ${ }^{[15]}$. Children, less than 5 years of age presented with abdominal mass, hematuria, hypertension, abdominal pain, and renal mass on ultrasound were enrolled. Data were collected and recorded on proforma. Plain and Contrast-enhanced abdominal CT scans including pelvis and chest regions were performed with multiple axial sections with coronal and sagittal reconstruction by TOSHIBA ASTEION 16 SLICE CT SCANNER. Statistics were done by package version 16 of SPSS windows. Descriptive analysis for example percentages and frequencies was conducted for variable categories like mean value, gender, and standard deviation was calculated for continuous variables like duration of symptoms, age of children, and tumor size. Specificity, sensitivity, negative predictive value, diagnostic accuracy, and positive predictive value of computed tomography in detecting Wilms' tumor were calculated by using histopathology as "Gold Standard" and followed by using $2 \times 2$ tables and figures and charts. Stratification to check their effects on results with regards to age, gender, and duration of symptoms. The Chi-square test was done by taking $\mathrm{P} \leq 0.05$ as significant after stratification.

\section{Results}

A total of 311 patients were analyzed. The mean \pm SD of the age was $3.5 \pm 1.2$ years (TABLE 1, FIGURE 1). There were $170(54.66 \%)$ males and 141(45.33\%) were females. (FIGURE 2) Mean \pm SD of the size of the tumor was $5.8 \pm 2.1 \mathrm{~cm}$. (TABLE 2, FIGURE 3 ).TABLE 3 shows the results of contrast-enhanced CT scan with histopathology. Figure 4 and Figure 5 demonstrate the left renal Wilms tumor on CECT.

Stratification of age, gender, duration of disease, and size of the tumor was done to analyze sensitivity, specificity, PPV, NPV, and diagnostic accuracy of CECT by using the chi-square test.

The diagnostic accuracy of CECT was $72.34 \%$, sensitivity $90.36 \%$, specificity $51.72 \%$, the positive predictive value of $68.18 \%$, and negative predictive value $82.42 \%$ by taking histopathology as a gold standard.

Table 1, Figure 1: Distribution of patients by age $(n=311)$

\begin{tabular}{|l|l|l|}
\hline Ages in year & No. of Patients & Per \% \\
\hline $1-2$ & 100 & 32.14 \\
\hline $3-4$ & 160 & 51.44 \\
\hline $5-6$ & 51 & 16.4 \\
\hline
\end{tabular}

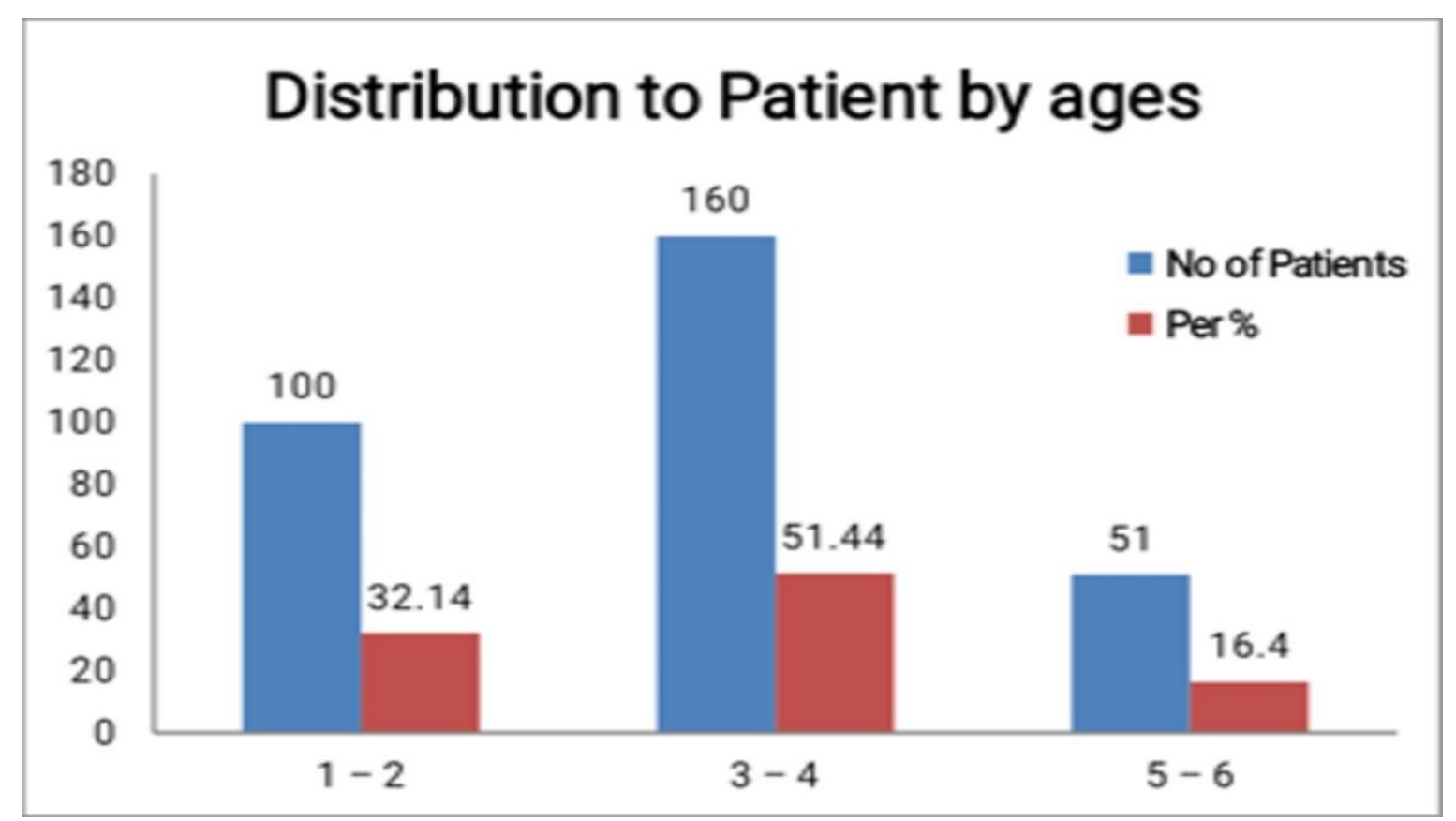




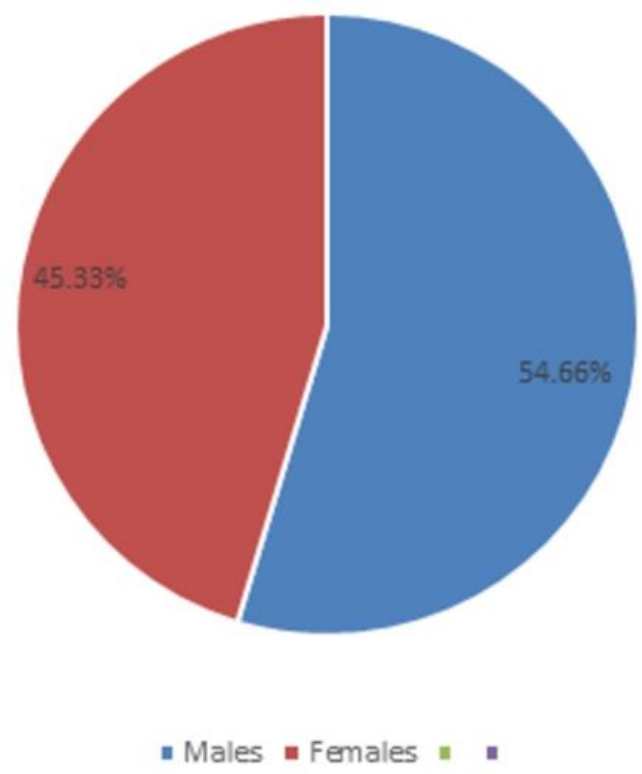

Figure 2: Distribution of patients by gender $(\mathrm{N}=311)$

Table 2, Figure 3: Distribution on the basis of size of tumor $(n=311)$

\begin{tabular}{|l|l|l|}
\hline Size of Tumor & No of Patients & Per \% \\
\hline $5-7$ & 180 & 57.87 \\
\hline $8-10$ & 90 & 28.93 \\
\hline $11-12$ & 41 & 13.13 \\
\hline
\end{tabular}

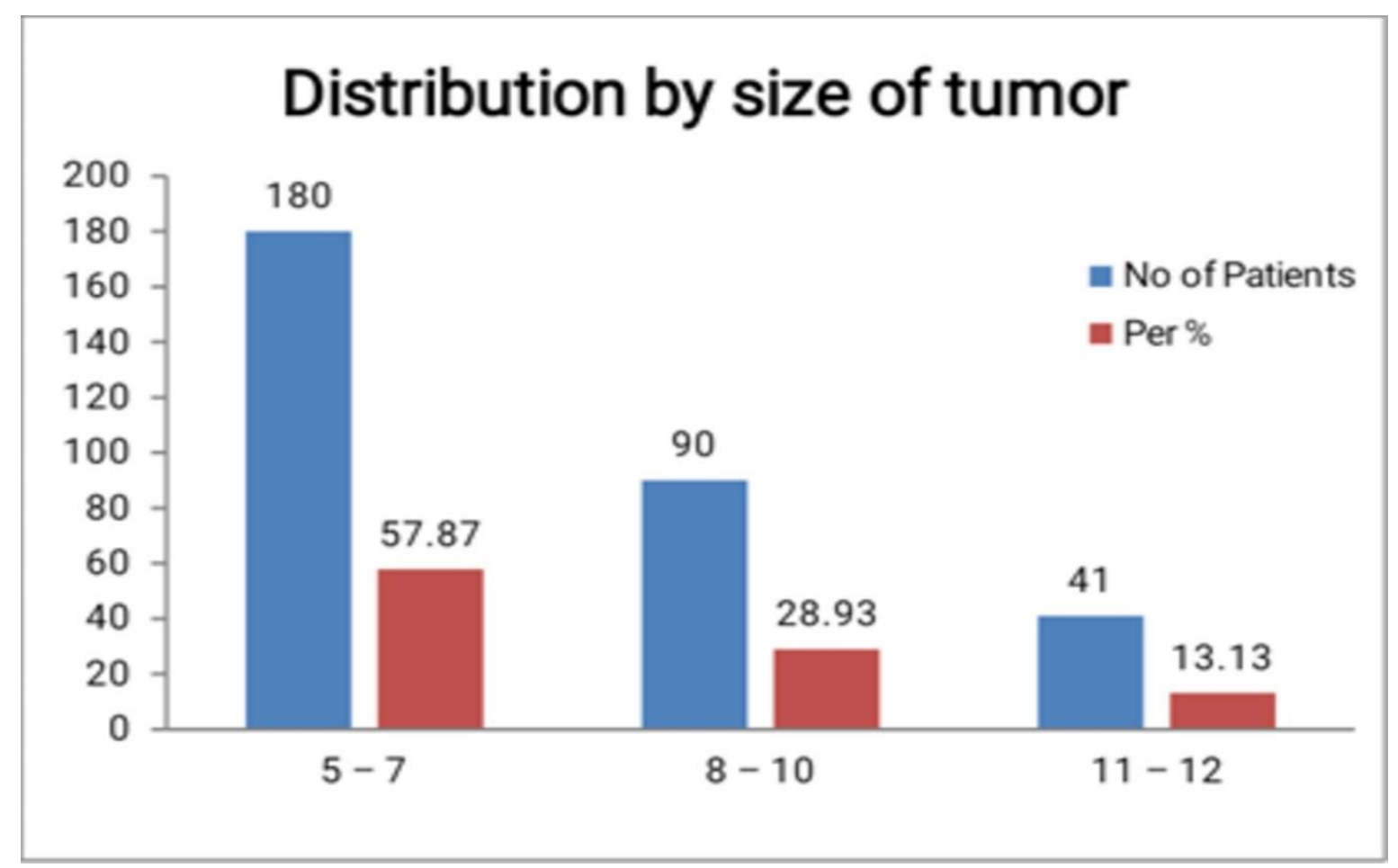

Table 3: Diagnostic accuracy of CECT in the detection of wilms tumor of kidney keeping histopathology as gold standard (n=311)

\begin{tabular}{|l|l|l|l|}
\hline \multirow{2}{*}{ Results Of Cect } & Histopathology & Total Cases \\
\cline { 2 - 4 } & Positive Cases & Negative Cases & \\
\hline CT & True positive (a) & False positive (b) & $\mathrm{a}+\mathrm{b}$ \\
(Positive) & 150 & 70 & 220 \\
\hline CT & False negative (c) & True negative (d) & $\mathrm{c}+\mathrm{d}$ \\
(Negative) & 16 & 75 & 91 \\
\hline TOTAL CASES & $\mathrm{a}+\mathrm{c}$ & $\mathrm{b}+\mathrm{d}$ & $\mathrm{N}$ \\
& 166 & 145 & 311 \\
\hline
\end{tabular}


Diagnostic Accuracy $=\frac{T P+T N}{T P+T N+F P+F N} \times 100$

Diagnostic Accuracy $=\frac{150+75}{150+75+70+16} \times 100$

Diagnostic Accuracy $=72.34$
Sensitivity $=\mathrm{a} /(\mathrm{a}+\mathrm{c}) \times 100=90.36 \%$

Specificity $=d /(d+b) \times 100=51.72 \%$

Positive P V = a / $(\mathrm{a}+\mathrm{b}) \times 100=68.18 \%$

Negative PV $=d /(d+c) \times 100=82.42 \%$
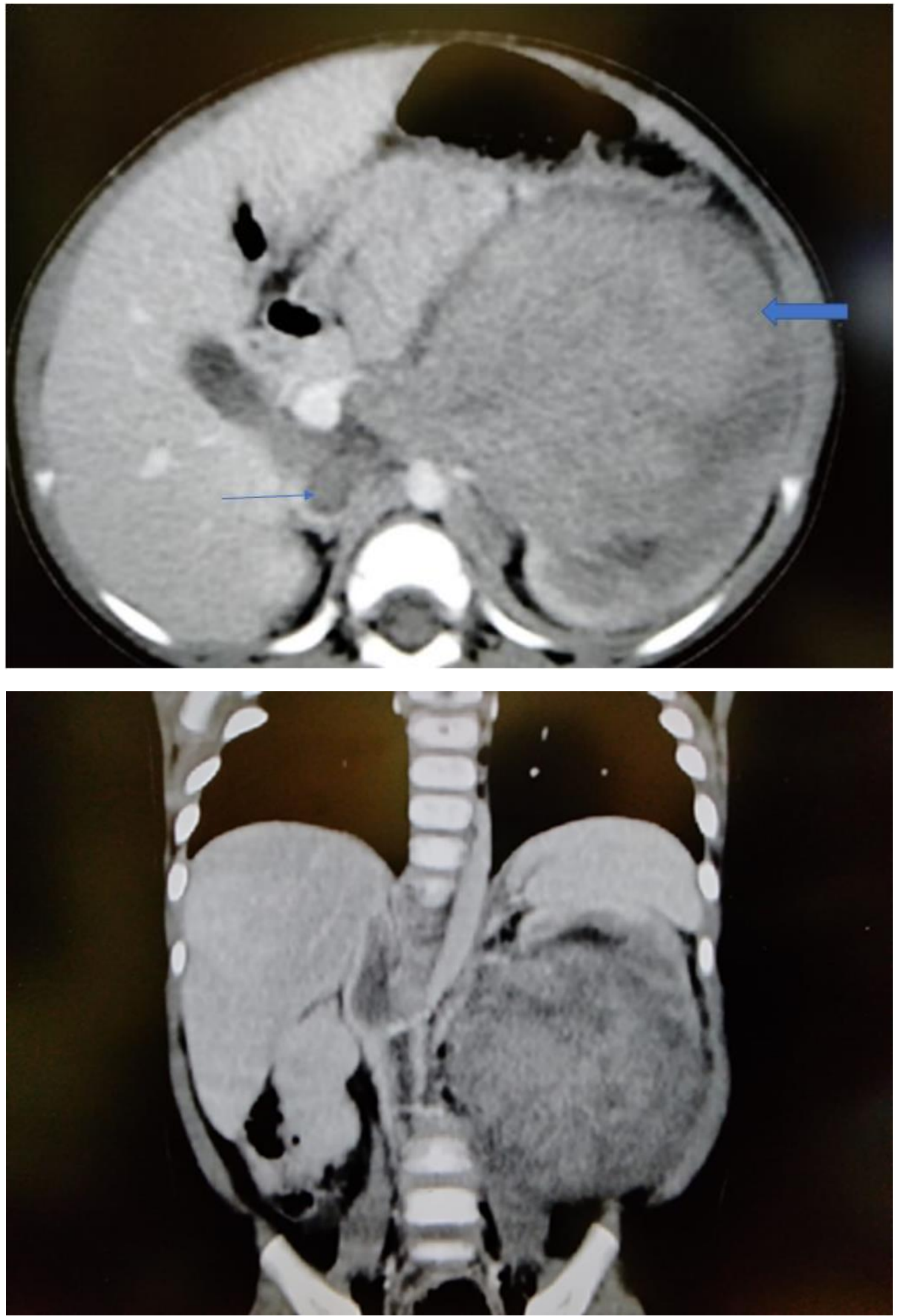

Figure 4,5: Axial and Coronal sections of Contrast enhanced CT scan shows left renal Wilms tumor with internal necrosis (Block Arrow) and IVC invasion (Arrow) 


\section{Discussion}

There is a vital role of imaging in the diagnosis of abdominal neoplasms. After clinical examination, the pediatric patients are attributed for the ultrasound abdomen however it is eminent that ultrasound is highly dependent on the operator. The next relevant imaging modality, is cross-sectional imaging, Abdominal CT, for tumor staging ${ }^{[11]}$. Various cross-sectional features are helpful for the precise characterization and diagnosis of the disease that impacts its outcome ${ }^{[16]}$. For the treatment of Wilms' tumor radiological size limitation of CT scan before the operation for staging lymph nodes, suspicious lymph nodes, and vascular invasion establish clinical and treatment effectiveness. Thus, a CT scan is an important tool for tumor staging. CT scan chest is also being performed, to ascertain pulmonary metastasis as lungs are the common location of metastasis ${ }^{[14]}$. In the past, the local extension of contrast-enhanced CT has some questions regarding its accuracy. In the study conducted by Gow et al, the correlation between CT and histopathology was poor ${ }^{[17]}$.

Our study embraces, the highest percentage of children were of 3-4 years of age and mean age of 3.5 years in comparison to the study of Silva and Silva in which the mean age was 4.4 years, which is comparable to our study. Furthermore, $54.6 \%$ of patients were male and $45.33 \%$ were females in our study, whereas in the study of Silva and Silva, males were $57.7 \%$ and $42.3 \%$ were females. In our population, the magnitude of tumor at the presentation time was $5-12 \mathrm{~cm}$, in comparison to the study of Silva and Silva where tumor size ranged between $7-12 \mathrm{~cm}{ }^{[18]}$. Histological assessment has been defined by the Children Oncology Group (COG) and The International Society of Pediatric Oncology (SIOP), in the literature. SIOP is a true believer of Chemotherapy cycles before surgery with a belief that upfront chemotherapy not only provides facilitation to remove the tumor surgically but also reduces intraoperative surgical complications. In the patients who are offered chemotherapy before the operation, the blastemal cell component in the tumor shows significant necrosis ${ }^{[7,19,20]}$.

The COG directs to follow chemotherapy and surgery and it also not only allows histopathology to characterize this tumor as focal or diffuse anaplasia but provides information about local staging, lymph nodal metastasis ${ }^{[7,19]}$.

There is always a question to effectively treat bilateral tumors. As surgery is an important tool in terms of maintaining renal function because synchronous tumors have a high rate of renal failure. The surgical management was previously a renal resection of the primary site, but now nephron-sparing surgery is considered after chemotherapy and hence now bilateral partial resection of the kidney is possible which has been a successful treatment $^{[3]}$.

The SIOP has designed a newer management protocol that has been pronounced as UMBRELLA PROTOCOL. This protocol continues to collaborate with countries throughout the world for primary pediatric renal cancers. This protocol takes account of the entry of a wide range of data. This also involves multispecialty including radiology. Their commitment is with both nephroblastomas and other renal tumors. They also look into account the volume of blastemal components, where chemotherapy is not successful. It also takes the expertise of the COG group and recommends its directions for locally invasive, metastatic, relapsed, and bilateral disease ${ }^{[21]}$.

The systemic synergetic approach towards this tumor management with multiple drug therapy presents an impressive survival of about $90 \%$ but the prognosis is unfruitful for children where histology is not favorable due to exorbitant cellular atypia.3 The absent paraaortic metastatic nodes, favorable histology, and early stages such as I and II are good prognostic signs ${ }^{[22]}$. Cytogenic assessment for $1 \mathrm{p}$, and $16 \mathrm{q}$ needs to be done even with favorable histology as these loci are having bad outcomes ${ }^{[17]}$. Lymph nodal, intrapulmonary, and hepatic metastasis is the most common consequence of this tumor ${ }^{[2]}$.

The aim in the future is to reduce the immediate and delayed toxicity of the treatment.

\section{Conclusion}

Our study proves significantly high diagnostic accuracy of contrast-enhanced CT, comparable to histopathology. This may provide accuracy of CECT to the clinicians in our population. It signifies the CT as a reliable tool for the precise characterization of tumors. Furthermore, CECT is a readily available, and noninvasive imaging modality. With the help of optimized CT images and proper phases, it also has a valuable role in tumor staging and its complications.

\section{Ethics approval and consent to participate}

The study was conducted after approval from Ethical Review Committee of Dr. Ziauddin University Hospital Karachi, Pakistan. The informed consent was obtained from all the parent's/guardians of the pediatric patients

\section{Data Availability}

The reader can access data by the following link: https://drive.google.com/file/d/1Y4D2TZy0GwEzWUompvflcFqA XY0vQue9/view?usp=sharing

\section{Conflict of Interest}

None

\section{Funding}

The study was self-funded

\section{References:}

[1] Diniz G. Histopathological and molecular characteristics of wilms tumor.

[2] McHugh K. Renal and adrenal tumours in children. Cancer imaging. 2007;7(1):41. PMID: 17339140. doi: 10.1102/1470-7330.2007.0007

[3] Davidoff AM. Wilms tumor. Current opinion in pediatrics. 2009 Jun;21(3):357. PMID: 1941766. doi: 10.1097/MOP.0b013e32832b323a

[4] Breslow N, Olshan A, Beckwith JB, Green DM. Epidemiology of Wilms tumor. Medical and pediatric oncology.

1993;21(3):172-81.

Doi:10.1002/mpo.2950210305

[5] Poole JE. Wilms' tumour (nephroblastoma). Continuing Medical Education. 2010;28(7):324-6.

[6] Memon F, Rathi SL, Memon MH. Pattern of solid paediatric malignant neoplasm at LUMHS, Jamshoro, Pakistan. Journal of Ayub Medical College Abbottabad. 2007;19(4):55-7. PMID: 25295119. DOI: 10.3892/ol.2014.2501 
[7] Wang J, Li M, Tang D, Gu W, Mao J, Shu Q. Current treatment for Wilms tumor: COG and SIOP standards. World Journal of Pediatric Surgery. 2019 Sep 1;2(3):e000038. doi: 10.1136/wjps-2019-000038

[8] Bhutani N, Kajal P, Sharma U. Many faces of Wilms Tumor: Recent advances and future directions. Annals of Medicine and Surgery. 2021 Mar 7:102202. PMID: 33747498. DOI: 10.1016/j.amsu.2021.102202

[9] Maciaszek JL, Oak N, Nichols KE. Recent advances in Wilms' tumor predisposition. Human molecular genetics. 2020 Oct 1;29(R2):R138-49. PMID: 32412586. DOI: $10.1093 / \mathrm{hmg} / \mathrm{ddaa} 091$

[10] Lugtenberg RT, Cransberg K, Loos WJ, Wagner A, Alders M, van den Heuvel-Eibrink MM. Topotecan distribution in an anephric infant with therapy resistant bilateral Wilms tumor with a novel germline WT1 gene mutation. Cancer chemotherapy and pharmacology. 2008 Nov 1;62(6):1039-44. DOI 10.1007/s00280-008-0694-x

[11] Servaes SE, Hoffer FA, Smith EA, Khanna G. Imaging of Wilms tumor: an update. Pediatric radiology. 2019 Oct;49(11):1441-52. Doi:10.1007/s00247-019-04423-3

[12] Just da Costa e Silva E, Alves Pontes da Silva G. Eliminating unenhanced CT when evaluating abdominal neoplasms in children. American Journal of Roentgenology. $2007 \quad$ Nov; 189(5): 12114.doi.10.2214/AJR.07.2154

[13] Friedman AD. Wilms tumor. Pediatr Rev. 2013 Jul 1;34(7):328-30. PMID: 23818087. DOI: 10.1542/pir.347-328

[14] Gupta AK, Chowdhury V, Khandelwal N. Diagnostic radiology paediatric imaging. JP Medical Ltd; 2011.

[15] Miniati D, Gay AN, Parks KV, Naik-Mathuria BJ, Hicks J, Nuchtern JG, Cass DL, Olutoye OO. Imaging accuracy and incidence of Wilms' and non-Wilms' renal tumors in children. Journal of pediatric surgery. $2008 \mathrm{Jul}$ 1;43(7):1301-7. doi.org/10.1016/j.jpedsurg.2008.02.077

[16] Rasool M, Pansota MS, Mumtaz F, Saleem MS, Tabassum SA. Positive predictive value (PPV) of computed tomography in diagnosing wilms' tumor using histopathology as gold standard. The Professional Medical Journal. 2019 Oct 10;26(10):1755-9. Doi:10.29309/TPMJ/2019.26.10.4136

[17] Gow KW, Roberts IF, Jamieson DH, Bray H, Magee JF, Murphy JJ. Local staging of Wilms' tumor-computerized tomography correlation with histological findings. Journal of pediatric surgery. 2000 May 1;35(5):677-9.

[18] Silva EJ, Silva GA. Local behavior and lymph node metastases of Wilms' tumor: accuracy of computed tomography. Radiologia Brasileira. 2014 Jan; 47:9-13. PMID: 10813321. DOI: 10.1053/jpsu.2000.5941

[19] Davidoff AM. Wilms tumor. Advances in Pediatrics. 2012 Jan 1;59(1):247-67. PMID: 22789581. DOI: 10.1016/j.yapd.2012.04.001

[20] Lopes RI, Lorenzo A. Recent advances in the management of Wilms' tumor. F1000Research. 2017;6. PMID: 28620463. doi: 10.12688/f1000research.10760.1

[21] Van Den Heuvel-eibrink MM, Hol JA, Pritchard-Jones K, Van Tinteren H, Furtwängler R, Verschuur AC, Vujanic GM, Leuschner I, Brok J, Rübe C, Smets AM. Rationale for the treatment of Wilms tumour in the UMBRELLA SIOP-RTSG 2016 protocol. Nature Reviews Urology. 2017 Dec;14(12):743-52. PMID: 29089605. doi.org/10.1038/nrurol.2017.163

[22] Leslie SW, Sajjad H, Murphy PB. Wilms tumor (nephroblastoma). StatPearls [Internet]. 2020 Jul 1.

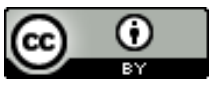

Open Access This article is licensed under a Creative Commons Attribution 4.0 International License, which permits use, sharing, adaptation, distribution and reproduction in any medium or format, as long as you give appropriate credit to the original author(s) and the source, provide a link to the Creative Commons license, and indicate if changes were made. The images or other third party material in this article are included in the article's Creative Commons license, unless indicated otherwise in a credit line to the material. If material is not included in the article's Creative Commons license and your intended use is not permitted by statutory regulation or exceeds the permitted use, you will need to obtain permission directly from the copyright holder. To view a copy of this license, visit

https://creativecommons.org/licenses/by/4.0/.

(c) The Author(s) 2021 